Article

\title{
Prescribed Burning Reduces Large, High-Intensity Wildfires and Emissions in the Brazilian Savanna
}

\author{
Filippe L.M. Santos ${ }^{1,2}{ }^{\mathbb{D}}$, Joana Nogueira ${ }^{3} \mathbb{D}$, Rodrigo A. F. de Souza ${ }^{2,4} \mathbb{D}$, Rodrigo M. Falleiro ${ }^{5}$, \\ Isabel B. Schmidt ${ }^{6}$ and Renata Libonati $1,7,8, *$ (D)
}

1 Departamento de Meteorologia, Instituto de Geociências, Universidade Federal do Rio de Janeiro, Rio de Janeiro 21941-916, RJ, Brazil; flms.dcl20@uea.edu.br

2 Programa de Pós-Graduação em Clima e Ambiente (CLIAMB), Instituto Nacional de Pesquisas da Amazônia (INPA)/Universidade do Estado do Amazonas (UEA), Manaus 69060-001, AM, Brazil; rafsouza@uea.edu.br

3 Institut für Landschaftsökologie, Westfälische Wilhelms (WWU), Universität Münster, 48149 Münster, Germany; joana.nogueira@uni-muenster.de

4 Escola Superior de Tecnologia, Universidade do Estado do Amazonas, Manaus 69050-020, AM, Brazil

5 Instituto Brasileiro de Meio Ambiente e Recursos Naturais Renováveis (Ibama), Brasília 70818-900, DF, Brazil; rodrigo.falleiro@ibama.gov.br

6 Departamento de Ecologia, Instituto de Ciências Biológicas, Universidade de Brasília, Brasília 70910-900, DF, Brazil; isabels@unb.br

7 Forest Research Centre, School of Agriculture, University of Lisbon, 1349-017 Lisbon, Portugal

8 Instituto Dom Luiz (IDL), Faculdade de Ciências, Universidade de Lisboa, 1749-016 Lisboa, Portugal

* Correspondence: renata.libonati@igeo.ufrj.br; Tel.: +55-21-968910078

Citation: Santos, F.L.M.; Nogueira, J.; Souza, R.A.F.d.; Falleiro, R.M.;

Schmidt, I.B.; Libonati, R. Prescribed Burning Reduces Large, HighIntensity Wildfires and Emissions in the Brazilian Savanna. Fire 2021, 4, 56. https://doi.org/10.3390/fire4030056

Academic Editors: João Neves Silva and Duarte Oom

Received: 21 June 2021

Accepted: 25 August 2021

Published: 2 September 2021

Publisher's Note: MDPI stays neutral with regard to jurisdictional claims in published maps and institutional affiliations.

Copyright: (c) 2021 by the authors. Licensee MDPI, Basel, Switzerland. This article is an open access article distributed under the terms and conditions of the Creative Commons Attribution (CC BY) license (https:// creativecommons.org/licenses/by/ $4.0 /)$.
Abstract: Brazil has recently (2014) changed from a zero-fire policy to an Integrated Fire Management (IFM) program with the active use of prescribed burning (PB) in federal Protected Areas (PA) and Indigenous Territories (IT) of the Brazilian savanna (Cerrado). PB is commonly applied in the management of fire-prone ecosystems to mitigate large, high-intensity wildfires, the associated emissions, and high fire suppression costs. However, the effectiveness of such fire management in reducing large wildfires and emissions over Brazil remains mostly unevaluated. Here, we aim to fill the gap in the scientific evidence of the PB benefits by relying on the most up-to-date, satellitederived fire datasets of burned area (BA), fire size, duration, emissions, and intensity from 2003 to 2018. We focused on two Cerrado ITs with different sizes and hydrological regimes, Xerente and Araguaia, where IFM has been in place since 2015. To understand fire regime dynamics, we divided the study period into three phases according to the prevalent fire policy and the individual fire scars into four size classes. We considered two fire seasons: management fire season (MFS, which goes from rainy to mid-dry season, when PBs are undertaken) and wildfires season (WFS, when PBs are not performed and fires tend to grow out of control). Our results show that the implementation of the IFM program was responsible for a decrease of the areas affected by high fire recurrence in Xerente and Araguaia, when compared with the Zero Fire Phase (2008-2013). In both regions, PB effectively reduced the large wildfires occurrence, the number of medium and large scars, fire intensity, and emissions, changing the prevalent fire season from the WFS to the MFS. Such reductions are significant since WFS causes higher negative impacts on biodiversity conservation and higher greenhouse gas emissions. We conclude that the effect on wildfires can still be reduced if effective fire management policies, including $\mathrm{PB}$, continue to be implemented during the coming decades.

Keywords: fire management; fire policy; remote sensing; burned area; scar size; savanna

\section{Introduction}

Savanna ecosystems encompass around $20 \%$ of the world's land surface, one of the most fire-prone landscapes [1,2], contributing to approximately $60 \%$ of gross global mean fire emissions [1]. Over the past two decades, savanna biomes have been subjected to 
changes in fire policies, land use, and climate, with significant impacts on the natural fire regime, such as increased extreme and intense wildfire events, emissions, and changes in fire size seasonality [2]. Savannas are characterized by rainy summers and dry winters, during which the grassy plant layer dries and turns into fine fuel, allowing for fire spread. The climatological and biophysical conditions (namely, high temperatures, low precipitation rates, and low fuel moisture) in the late-dry-season promote quickly spreading fires, which can become wildfires, resulting in large burned areas, severe environmental and economic damages, high carbon emissions, and high firefighting costs. A recent study showed that the majority of burned area (BA) in savannas was due to fires in the late-dry-season [3], suggesting that an integrated approach by intentionally shifting the fire regime from late-dry-season to early- or mid-dry-season provides an immediate and practical solution to reduce emissions, manage wildfire risks, and conserve biodiversity [4]. Prescribed burning (PB) is a commonly used technique to reduce fuel loads of fire-prone ecosystems worldwide. These management burns are performed within fire management programs, aiming to mitigate large, high-intensity wildfires, the associated emissions, and high fire suppression costs [5]. PB is generally performed during dry spells in the rainy season or the early to mid-dry-season. PB aims to create landscape mosaics with different fire histories to reduce the areas affected by wildfires and decrease wildfire frequency in fire-sensitive vegetation, such as riparian forests within the savanna matrix [6]. Indeed, PB is recognized as a climate mitigation strategy in fire-prone ecosystems since low-intensity fires do not consume all the fine fuel and, consequently, release less greenhouse gas (GHG) than wildfires $[3,7,8]$. This strategy is especially relevant since national public policies are essential to meet the climate change goal of the Paris Agreement through GHG emissions reduction [9].

The evaluation of $\mathrm{PB}$ as a fire management tool for meeting wildfire hazard reduction has been reported in several countries, such as the USA, Australia, Portugal, and South Africa [3,10-14]. However, similar analyses are lacking over South America, especially Brazil, largely due to the very recent adoption of fire management policies applying and regulating PB [15]. For several decades, Brazil's fire policy has sought to avoid all fires, even in fire-prone ecosystems, such as the Brazilian savanna (Cerrado) [16,17]. "Zero-fire" policies, i.e., prohibition of fire use and attempting to prevent and control any type of fire, are recognized as leading to fuel accumulation, which in turn contributes to large wildfires in fire-prone ecosystems [8]. These intense fires usually occur in the late-dry-season and can reach a considerable extent, particularly in fire-sensitive ecosystems, negatively affecting biodiversity, homogenizing landscapes [18], emitting a large amount of GHG and particulate matter to the atmosphere [19], threatening animals [20], exposing property and people to risk, and generating high suppression costs [17,21]. During the zero-fire policy period, dry fuel accumulation led to large wildfires in the Brazilian savanna [22,23], and high biodiversity losses were reported [24]. The paradigm shift from fire suppression to management policies started in 2012 with a federal legislation shift that explicitly allowed fire management in private and public protected areas [25]. In 2014, acknowledging the pervasive consequences of the zero-fire policy, the Brazilian government started an Integrated Fire Management (IFM) program in federal Protected Areas (PA), including Indigenous Territories (IT) of the Cerrado based on three main objectives: (i) to decrease late-dry-season wildfires; (ii) to change of the prevalent burning season from late- to earlyor mid-dry-season and (iii) to protect fire-sensitive vegetation. The program was centered on low-intensity PB use [26].

In this context, there is an increasing need to provide comprehensive evidence on which to base the effects of PB for reducing large wildfires and their impacts. In this way, meaningful advances in Earth observation technology in recent decades have allowed the compilation of long-term fire datasets with reasonable spatial resolution and improved accuracy [27]. Newly developed tools and methodologies enable distinguishing single fire events [28-30] based on burn date and provide accurate burning location and duration information [31], as well as fire characteristics related to fire size [32-36]. Accordingly, 
remote sensing techniques have helped identify fire patterns, characteristics, and changes worldwide, including tracing burning patterns resulting from fire management efforts [37]. However, few studies have focused on such satellite-derived databases to analyze PB patterns in Brazil. Emergent literature seeks to show how PB has been contributing to decreasing wildfires in Brazilian savannas, mainly based on field campaigns or local observation $[25,26,38-44]$. The majority of those studies rely on statistical summaries of active fire counts and total values of BA $[6,39,43,45,46]$. Therefore, a systematic analysis considering additional fire characteristics, such as fire intensity, date of burn occurrence, emissions, and patchiness, is urgently needed to enable further characterization of PB benefits.

Here, we aim to analyze how PB implementation affects the occurrence of large wildfires, relying on the most up-to-date satellite-derived fire datasets of BA, fire size, fire danger, fire intensity, and associated emissions from 2003 to 2018. We focus on two ITs over the Cerrado, namely Xerente and Araguaia, where PB has been conducted regularly within the IFM program since 2015. We examine variations in fire regime defining three distinct fire policy and management phases: No Fire-policy Phase (NFP)—from 2003 to 2007, a period characterized by an absence of fire policies; Zero Fire Phase (ZFP) - from 2008 to 2013, when the zero-fire approach (fire use prohibition to manage the landscape) was prevalent; Integrated Fire Management Phase (IFMP)—from 2014 to 2018 when the IFM was implemented.

\section{Materials and Methods}

\subsection{Study Region}

The Cerrado is a mosaic of water dynamics and different ecosystems [47] that are subject to high intra-annual variability in precipitation [48] and a well-defined dry season in winter, generally from May to October [49]. According to Silva et al. [50], the fire intraannual trends Cerrado is spatially heterogeneous with marked north-south fire activity gradient, with increasingly large and less intense fires in the latest agricultural frontier in the north. More intense fires are found in the Amazon frontier biome due to uncontrolled deforestation and different histories of land conversion. Throughout the year, the infrequent large fires occur in late-dry-season and are responsible for the majority of burned area, whereas smaller fires, albeit more frequent in early-dry-season, have been decreasing in number [50].

The two study areas encompass the Indigenous Territories of Xerente and Parque Araguaia, located in the state of Tocantins within Cerrado (Figure 1a), hereafter Xerente and Araguaia, respectively. These two territories were homologated by the federal government in 1989 and 1998, respectively [51]. These areas have a tropical wet-dry climate, according to Köppen-Geiger's definition, with annual precipitation above $1600 \mathrm{~mm}$, with $85 \%$ concentrated from November to April, i.e., mean rainfall in the dry season months is below $80 \mathrm{~mm} / \mathrm{month}$. The yearly average temperature is $24.9^{\circ} \mathrm{C}$, with the hottest months being August, September, and October [52].

Xerente covers 162,542 ha, with the indigenous population [53] distributed in small settlements throughout the territory and an economy based on social programs, public jobs, itinerant agriculture, hunting, gathering, and handcrafts. They possess a vast traditional knowledge of how to manage the Cerrado with fire, which is used to plan PB activities. Araguaia covers 1,358,499 ha of the largest river island in the world (Bananal Island) [54]. The villages are distributed along the Araguaia and Javaé rivers, and the island's interior is sparsely populated. These areas are flat, subject to flooding, and dominated by native grasslands used for grazing in partnership with non-indigenous ranchers. Biomass production is very high in these areas, allowing extreme and frequent fire events, often associated with cattle activities [55]. 

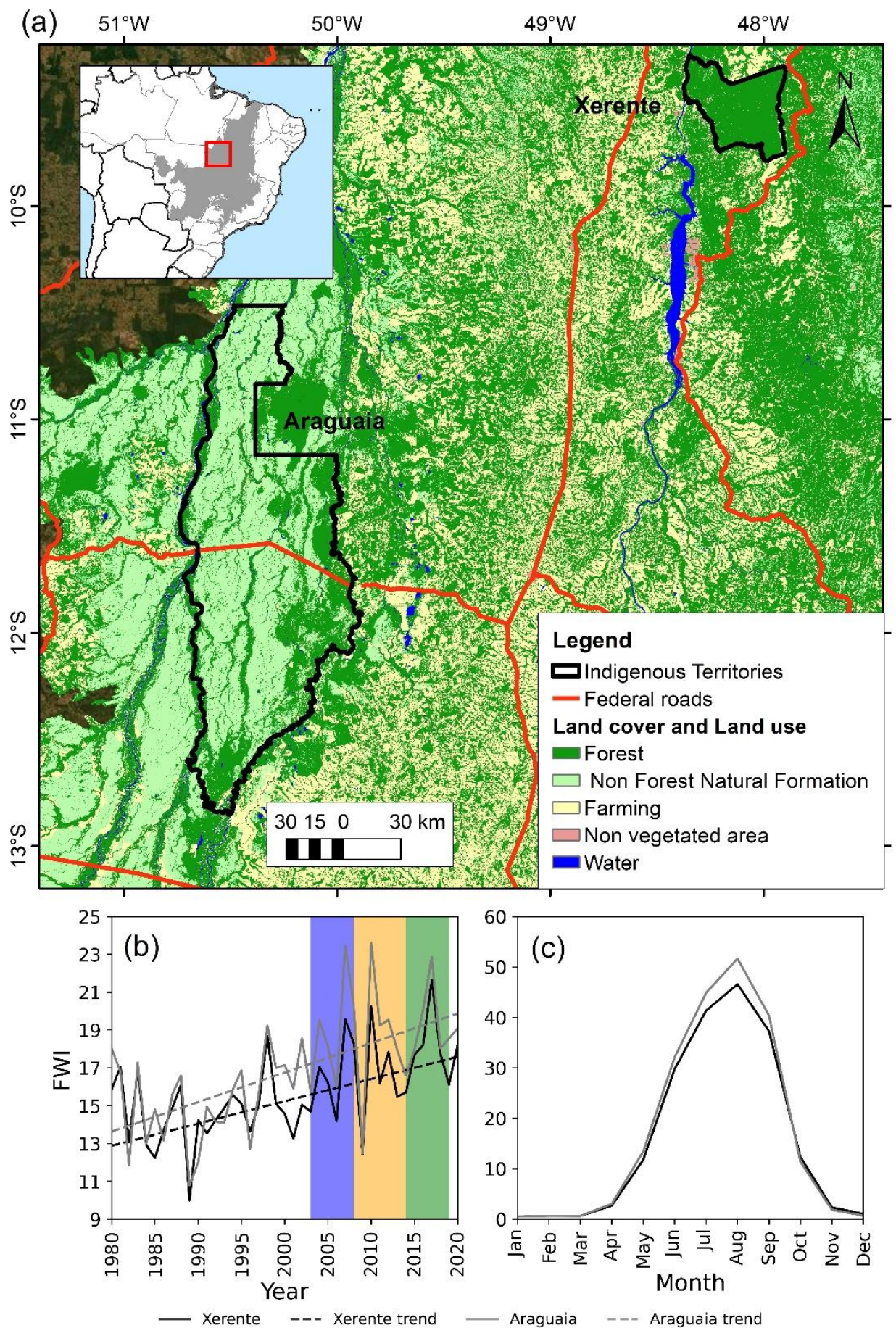

Figure 1. (a) Study area location: Xerente and Araguaia ITs, located in the Northern Cerrado (grey in the small panel) over Brazil. Land cover and land use information are derived from the MapBiomas Collection 5 [44] dataset and shown for 2019. (b) Fire Weather Index (FWI) annual values from 1980 to 2020 for Xerente (black) and Araguaia (grey). Dashed lines represent the trendline obtained using nonparametric Theil-Sen Robust Linear Regression (TS) and a two-tailed Mann-Kendall (MK) test of significance. NFP, ZFP, and IFMP are highlighted in blue, yellow and green, respectively. (c) FWI intra-annual variability for Xerente (black) and Araguaia (grey).

Among the ITs served by the IFM program, Xerente and Araguaia have the longest history of official PB implementation [46]. Xerente received the first fire control activities in 2008 based on zero-fire policies through the Tocantínia municipal brigade, composed mainly of indigenous people. From 2014, fire began to be increasingly used in land man- 
agement. Xerente became one of the model brigades, and its brigades have been frequently requested to help in management and firefighting operations around the country [56]. Araguaia also received the first fire protection programs in 2008, generally associated with brigades located in nearby municipalities, with little indigenous participation. Fire use was prohibited, and major combat operations were registered in the savannas. Since 2014, with the indigenous brigade's implementation and the IFM program beginning, firefighting operations in savanna areas have reduced, but they still occur in forest areas. In these two regions, the IFM program's implementation included the professionalized indigenous brigade's training, vehicles, infrastructure, and safety equipment. The aim is to use local traditional knowledge in defining the fire regimes to be implemented $[57,58]$.

\subsection{Fire, Climate, and Emissions Datasets}

We used 5 datasets, which were as follows: (i) PB locations and dates provided by the IBAMA/PREVFOGO (the Brazilian Environmental Agency responsible for the IFM program in TIs); (ii) individual fire scars from the Global Fire Atlas (GFA) database [31]; (iii) Fire Radiative Power (FRP) information derived from MCD14ML active fire product [59]; (iv) Fire Weather Index (FWI), derived from the ERA5 climate reanalysis [60]; and (v) fine particulate matter $\left(\mathrm{PM}_{2.5}\right)$ concentrations derived from the Copernicus Atmosphere Monitoring Service (CAMS) [61]. These are described in detail below and summarized in Table 1.

PB information, derived by IBAMA/PREVFOGO, encompasses the geographical coordinates (latitude/longitude in degrees) and dates (in Julian days) carried out from 2015 to 2018. This period was when the IFM began its implementation over the two study regions; however, the extent of $\mathrm{PB}$ is not available.

GFA is a global fire database derived from the MCD64A1 BA collection 6 product [31] that provides individual fire characteristics based on the information generated by 8 -day images from the MODIS satellite [62]. Here, we relied on individual fire scars over the study region containing scar size (ha) and date of occurrence (Julian day) from 2003 to 2018. Since GFA is based on the MCD64A1 500-m product, the smallest BA mapped is around 25 ha, precluding the identification of very small scars [31]. As PB may be small, there is no guarantee that this satellite-derived database can detect all burned areas from the IFM program. Thus, for the sake of simplicity, we assumed that GFA scars account for all fires, indistinguishably, both planned and unplanned.

FRP represents a measure of the instantaneous release of combustion energy and is associated with the fire intensity of the burning process [50]. We used FRP (MW) data derived from $1 \mathrm{~km}$ MODIS/Aqua Thermal Anomalies/Fire locations from 2003 to 2018, and only pixels with presumed vegetation fires (type 0 ) were used to minimize false alarms. The MCD14ML FRP product has limited detection above the threshold of 9-11 MW [63]. However, very low FRP mainly occurs away from the diurnal peak of fire activity in Cerrado (between 15-18h local time) [64], thus not impairing our assessments.

FWI is based on the ERA5 reanalysis variables from the European Centre for MediumRange Weather Forecasts (ECMWF) [65], namely, the daily values of air temperature and relative humidity at $2 \mathrm{~m}$-height, wind speed at $10 \mathrm{~m}$-height, and total precipitation, from 1979 until the present. FWI provides a complete historical reconstruction of meteorological conditions favorable to the start, spread, and sustainability of fires and is based on two indices-namely, Initial Spread Index and Build-Up Index - which are the fire spread rate and fuel available for combustion, respectively [60]. This is one of the most reliable and globally applied fire weather indices and has shown to be particularly suitable to rate meteorological fire danger for the Cerrado ecosystems [49,66-68]. Here, we used information from 1980 to 2020 at $0.25^{\circ}$ spatial resolution.

We used the monthly $\mathrm{PM}_{2.5}$ values from the fourth-generation global CAMS reanalysis dataset (EAC4) [61] with $0.75^{\circ}$ spatial resolution. $\mathrm{PM}_{2.5}$ refers to particles with a diameter of less than $2.5 \mu \mathrm{m}$ and remain suspended longer in the air than heavier particles, where 
fires are one of their main sources [69]. It is worth mentioning that the EAC4 dataset can ensure good temporal consistency [61].

Table 1. Description of the variables and datasets used in this study.

\begin{tabular}{|c|c|c|c|c|c|}
\hline Variable [Unit] & Dataset & $\begin{array}{c}\text { Spatial } \\
\text { Resolution }\end{array}$ & $\begin{array}{c}\text { Serie and } \\
\text { Temporal } \\
\text { Resolution }\end{array}$ & Source & Reference \\
\hline Prescribed burning counts & IBAMA/PREVFOGO & not applied & $\begin{array}{l}\text { daily, } \\
\text { 2015-2018 }\end{array}$ & $\begin{array}{l}\text { IBAMA/ } \\
\text { PREVFOGO }\end{array}$ & $\begin{array}{c}\text { personal } \\
\text { communication }\end{array}$ \\
\hline Scar size [ha] & $\begin{array}{l}\text { Global Fire Atlas (GFA) } \\
\text { database }\end{array}$ & $500 \mathrm{~m}$ & $\begin{array}{l}\text { daily, } \\
\text { 2003-2018 }\end{array}$ & [70] & [31] \\
\hline Fire intensity [MW] & $\begin{array}{l}\text { MCD14ML active fire } \\
\text { product }\end{array}$ & $1 \mathrm{~km}$ & $\begin{array}{c}\text { daily, } \\
\text { 2003-2018 }\end{array}$ & {$[71]$} & [59] \\
\hline Fire Weather Index (FWI) & Fire danger indices & $0.25^{\circ}$ & $\begin{array}{c}\text { daily, } \\
1979-2020\end{array}$ & [72] & [65] \\
\hline $\begin{array}{c}\text { Particulate matter } \\
\mathrm{d}<2.5 \mu \mathrm{m}\left(\mathrm{PM}_{2.5}\right) \\
{\left[\mathrm{kg} \cdot \mathrm{m}^{-3}\right]}\end{array}$ & $\begin{array}{l}\text { Copernicus Atmosphere } \\
\text { Monitoring Service } \\
\text { (CAMS) database }\end{array}$ & $0.75^{\circ}$ & $\begin{array}{l}\text { monthly, } \\
\text { 2003-2018 }\end{array}$ & [73] & [61] \\
\hline
\end{tabular}

\subsection{Pre-Processing and Statistical Analysis}

We analyzed temporal patterns and changes of $\mathrm{PB}$ and climate in each region. To this end, the number and location of PBs conducted since 2015 were analyzed. Moreover, climate trends in each region were analyzed from 1980 until 2020 through FWI. We searched for significant trends using the nonparametric Theil-Sen Robust Linear Regression (TS) and a two-tailed Mann-Kendall (MK) test of significance [74,75]. The TS estimator is robust against outliers and suitable for application in time series with significant interannual variations, such as annual fire counts, precipitation, and deforestation $[76,77]$. The null distribution of the MK test statistics follows a normal distribution when $n \geq 8[74,75]$. The $\mathrm{p}$-value of an MK statistic was then determined using the normal cumulative distribution function [78]. The trend analysis was conducted to analyze the FWI values dataset for each region through pyMannKendall, a package in the python programming language [79].

Then, we performed a comprehensive analysis of BA and the total number of scars during the last two decades using the GFA dataset, according to 4 scar size classes: very small (VS, 0-50 ha); small (S, 50-100 ha); medium (M, 100-1000 ha); large (L, >1000 ha), based on previous works [50,80-82]. For each scar size class, we conducted separate analyses for the 2 fire seasons, determined by management practices: management fire season (MFS) encompassing the months when PBs are conducted, and wildfire season (WFS), corresponding to the months when PBs are not conducted, and fires are considered "bad-fires" by local inhabitants. The MFS was determined in each IT based on local ecological knowledge, as the periods when fire impacts on biodiversity reduce due to biophysical conditions, plant phenology (especially flowering and fruiting periods), and animal reproduction/nesting/nursing periods [16,46,83,84]. In Xerente, PBs are carried out from January to June (MFS), whereas any fires between July and December are considered wildfires (WFS). Due to soil flooding dynamics, the MFS in Araguaia extends from January to July, and the WFS from August to December [46]. As mentioned before, the IFM program implemented in 2015 over Cerrado has 3 main objectives: (I) to decrease late-dry-season wildfires; (II) to distribute fires over the year, decreasing extreme wildfire damages in the late-dry-season; (III) to protect fire-sensitive vegetation. Here, we aim to evaluate IFM objectives (I) and (II). Specifically, we addressed IFM objective (I) using 3 different approaches:

We divided the study period (2003-2018, where satellite-derived information is available) into 3 distinct phases: NFP consists of the period from 2003 to 2007 when there was almost a lack of consistent fire policies over the region [44], hereafter the "No Fire-policy Phase". ZFP includes the period from 2008 until 2013, when a total fire suppression policy, 
hereafter the "Zero Fire Phase", was applied [16,17,85]. Finally, IFMP goes from 2014 to 2018, thus representing the IFM implementation including "controlled" and "prescribed" burns, hereafter the "Integrated Fire Management Phase". To analyze the differences between phases, for each fire season, we first considered the changes between (i) NFP and ZFP and (ii) ZFP and IFMP, considering annual BA and scar number (SN) frequency in each IT.

First, we examined variations in annual fire patterns along with the 3 distinct fire policy phases and 2 fire season periods employing boxplots. Second, for the WFS, we compared the Kernel probability density function (PDF) of (i) daily BA for large scars, (ii) daily fire intensity, and (iii) monthly fire emission during the 3 phases, highlighting extreme events using the 90th percentile (hereafter BAp90, FRPp90, and PMp90, respectively) of each distribution. For those extreme-related indexes, we computed the percentage changes between (i) NFP and ZFP and (ii) ZFP and IFMP. Changes between phases were confirmed based on 1000 samples generated by the bootstrapping approach, which can be used to assess variation in confidence between independent variable samples [86].

Third, a spatial analysis was conducted to evaluate changes in fire recurrence of large fire scars along with the 3 phases. For each pixel, fire recurrence was defined as the average number of years with fire occurrence during each phase. Fire recurrence was classified into 3 classes: zero (no fire occurrence), low (less or equal than 0.6 fire occurrence per year), and high (greater than 0.6 fire occurrence per year). We analyzed the proportion of pixels (i.e., area) in each fire recurrence class and evaluated changes in this amount between the 3 phases.

To evaluate IFM objective II, we analyzed seasonal patterns and changes of BA distribution according to each scar size class, fire period, and phase.

\section{Results}

\subsection{Overview of $P B$, Fire and Climate Trends}

The number and geographical distribution of $\mathrm{PB}$ have increased in both study areas from 2015 until 2018 (Table 2 and Figures S1 and S2), according to the dataset derived by IBAMA/PREVFOGO. When the IFM program began, the PB number was low in both regions. However, $\mathrm{PB}$ is widespread around both regions after three years, increasing 8 and 70 times in Xerente and Araguaia, respectively.

Table 2. The number of Prescribed burning (PB) performed in the scope of the Integrated Fire Management (IFM) program figure 2015 to 2018 in each study area (Xerente and Araguaia).

\begin{tabular}{ccc}
\hline Year & Xerente & Araguaia \\
\hline 2015 & 44 & 11 \\
2016 & 40 & $*$ \\
2017 & 147 & 491 \\
2018 & 367 & 772 \\
\hline
\end{tabular}

* PB was not recorded in 2016, for logistic reasons.

Annual FWI values from 1980 to 2020 revealed a systematic increase in both regions since 1980, in response to higher regional temperatures and lower relative humidity and precipitation. FWI has increased by $31 \%$ and $47 \%$ over Xerente and Araguaia during the last four decades, respectively. In addition, we observed a positive and significant $(p<0.001)$ trend for both study areas with higher FWI values in Araguaia compared with Xerente (Figure 1b). The mean annual cycles of temperature, relative humidity, accumulated precipitation, and wind during the 40-year period are also represented through FWI (Figure 1c). Both regions present strong seasonality; the austral summer months are associated with very low values of FWI, reflecting high values of both relative humidity and precipitation (the rainy season). The higher values of FWI are observed between May and October, with maximum values in August, and consistent with the increasingly warmer and drier 
conditions over the region. Araguaia shows higher FWI values than Xerente, especially during the dry season.

During the MFS in Xerente, large scars were infrequent but account for around onequarter of the total BA (Figure 2a). In contrast, medium scars were more frequent and account for a large portion (65\%) of the total BA. In the WFS (Figure 2c), large scars represent just one-quarter of the total number of scars but account for more than $75 \%$ of total BA in the region. Conversely, very small and small, together represent around half and one-quarter of the fire scars in the MFS and WFS, respectively; however, their contribution to the total BA is negligible in both fire seasons.

In Araguaia, very small and small fires together account for less than $25 \%$ of scars and represent less than 1\% of the total BA in the MFS (Figure 2b) and WFS (Figure 2d). Medium scars prevail in both seasons, particularly during the MFS, though their contribution to the total BA is less than $25 \%(5 \%)$ in the MFS (WFS). In contrast, although less frequently, large scars correspond to more than 75\% (95\%) of the total BA in the MFS (WFS) (Figure 2b,d).

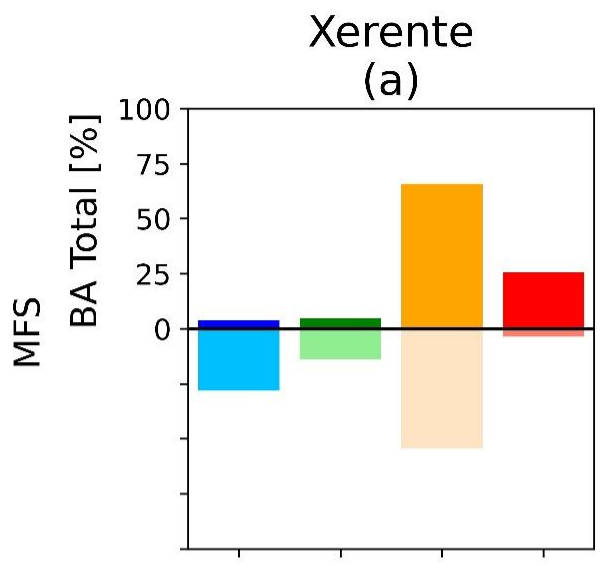

(c)

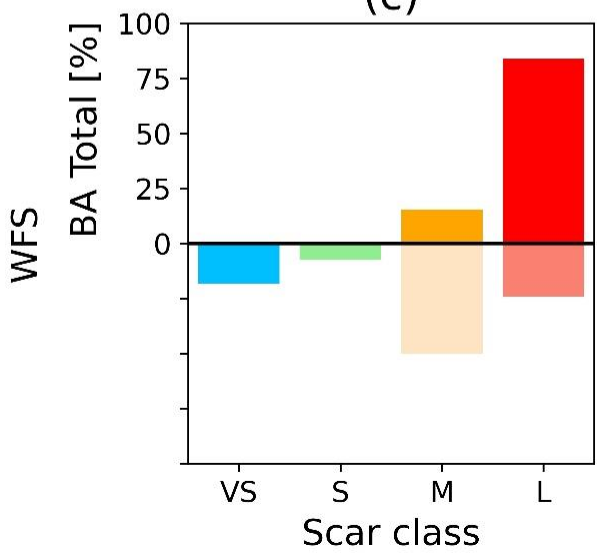

Araguaia

(b)

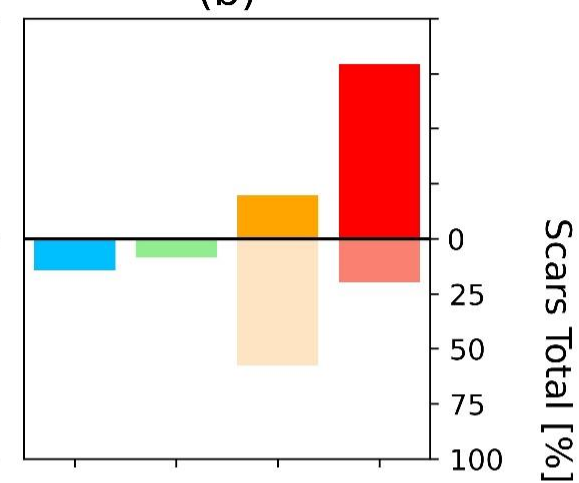

(d)

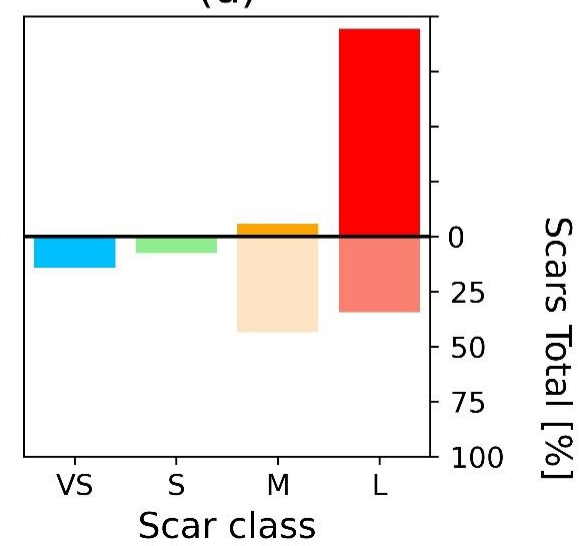

Figure 2. Total burned area (BA, \%, full color) and scars (\%, smoothed color) per scar size class: very small (VS, blue), small (S, green), medium (M, orange), and large (L, red) in the management fire season (MFS, upper row) and wildfire season (WFS, bottom row) from 2003 to 2018 in Xerente (a,c) and Araguaia $(\mathbf{b}, \mathbf{d})$.

\subsection{Observed Changes}

We compared annual BA (Figure 3a-d) and SN (Figure 3e-h) boxplots in each phase for Xerente (left columns) and Araguaia (right columns), focusing on how wildfire and management fire differ concerning the median and extreme values. For the MFS between NFP and ZFP, median values of annual BA (SN) decreased 67.8\% (60\%) in Xerente (Table S1). During the same period of change, in Araguaia, the reduction reached $47.4 \%$ for SN, but 
only $0.5 \%$ for BA. In contrast, median values of BA and SN during IFMP were $270 \%(660 \%)$ higher than ZFP for Xerente (Araguaia) (Table S1).
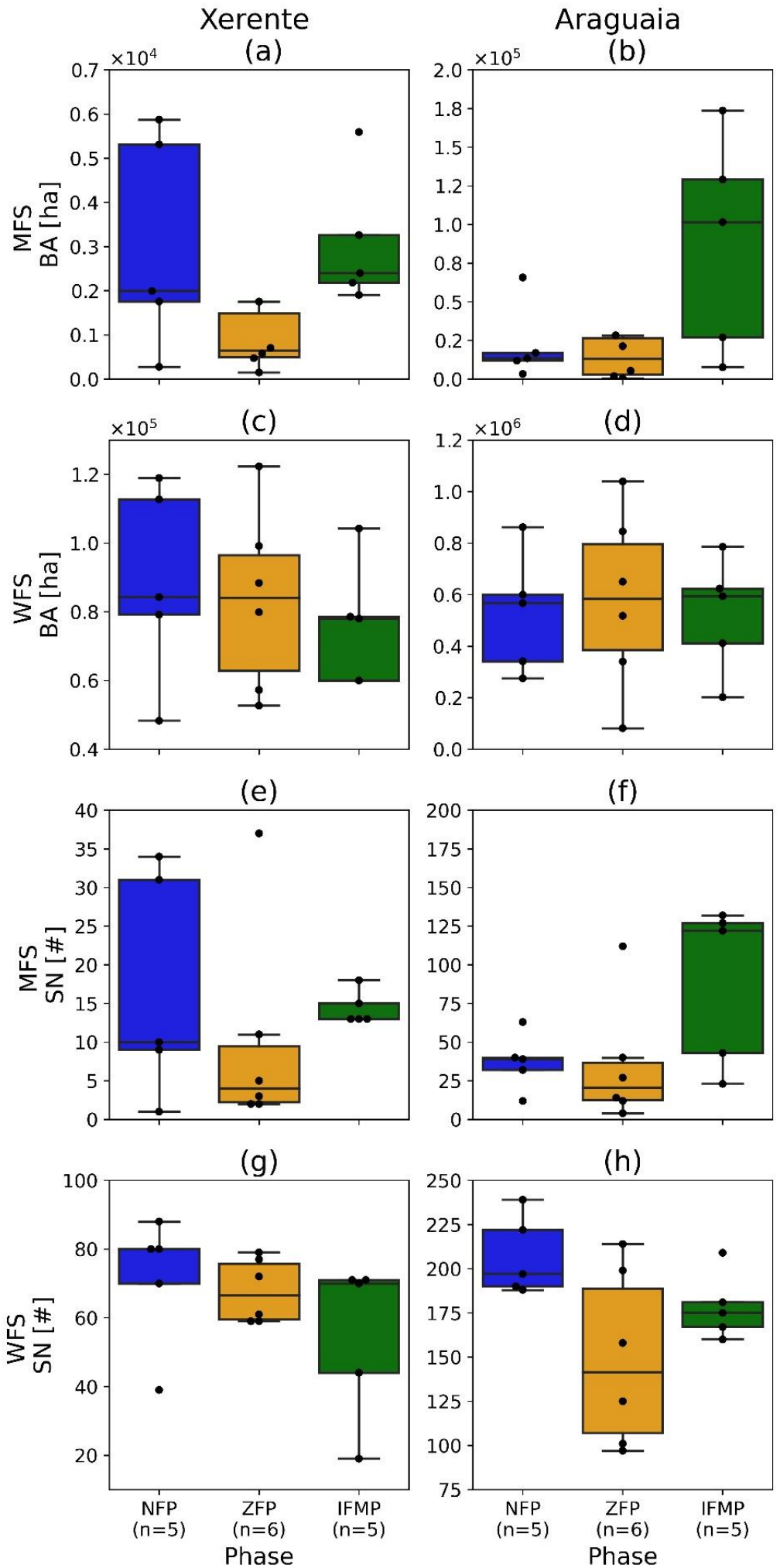

(h)

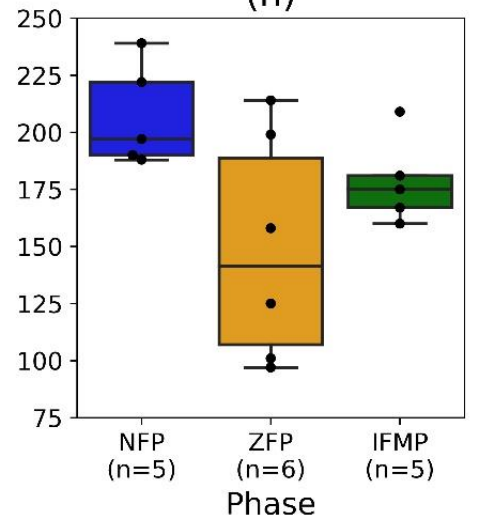

Figure 3. Boxplot for annual accumulated burned area (BA, a-d) and total scar number (SN, e-h) in MFS (a,b,e,f) and WFS (c,d,g,h) in the Xerente (left column) and Araguaia (right column) for each phase. Annual values are depicted in black dots. 
In the WFS, the medians for annual BA are all at the same level during the three phases for both regions. However, the boxplots show very different distributions of patterns. We observed that there is a greater variability for BA, as well as larger differences in extreme values in all phases. In those extreme cases, the reduction from ZFP to IFMP was $15.1 \%$ in Xerente and 23.5\% in Araguaia (Table S1). Regarding SN, the median values decreased from NFP to ZFP and increased from ZFP to IFMP, particularly for Araguaia. Again, looking for differences between the spreads of the groups, we observed that some phases are more variable than others.

Overall, these results demonstrated that (i) for the MFS, median annual values for BA and SN increased from ZFP to IFMP; and (ii) for the WFS, extreme annual values for BA decreased.

Figure 4 displays BA (for large scars), FRP, and $\mathrm{PM}_{2.5}$ probability density functions, and identifies the 90th percentile BAp90, FRPp90, and PMp90 for the three phases during the WFS. Most fires display lower BA and intensity in all periods, and therefore, median values provide very limited discrimination among the three periods. However, those distributions have heavy right tails; therefore, high percentiles, such as the 90th percentile, improve the discrimination between each period. The exception being $\mathrm{PM}_{2.5}$ distribution for Xerente, which did not show heavy tails.
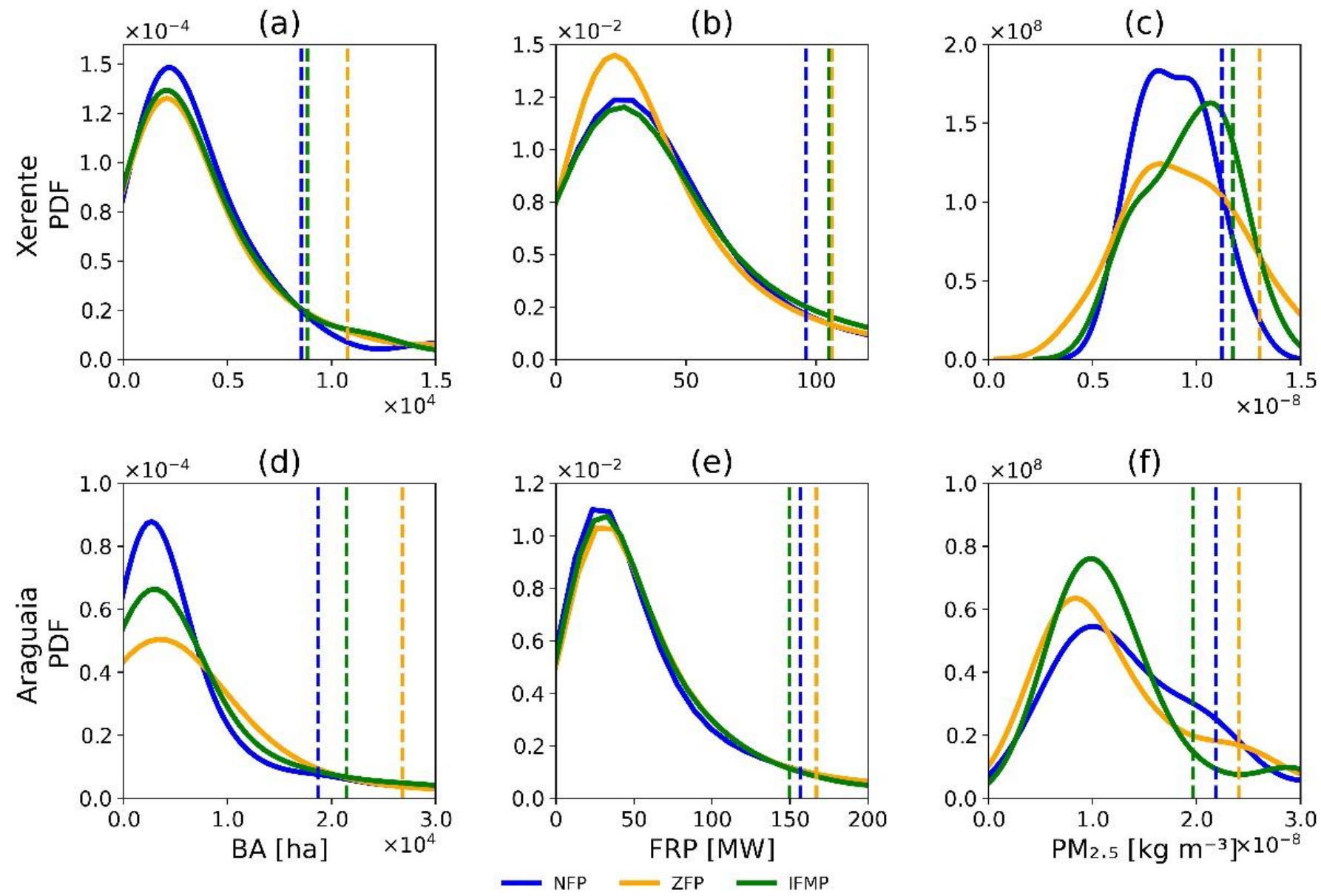

Figure 4. Kernel Probability density function (PDF) of burned area (BA, ha) for large scars (a,d), Fire Radiative Power (FRP, MW, b,e) and pyrogenic emission $\left(\mathrm{PM}_{2.5}, \mathrm{~kg} \cdot \mathrm{m}^{-3}, \mathbf{c}, \mathbf{f}\right)$ for WFS during each phase (NFP-blue, ZFP-yellow, IFMPgreen) for in the Xerente (upper row) and Araguaia (bottom row). The dashed lines represent the 90th percentile for each respective phase.

WFS values of BAp90 were much higher during ZFP compared with NFP and IFMP (Figure 4). In Xerente (Araguaia), BAp90 increased 26.3\% (43.5\%) from NFP to ZFP and 
decreased $17.9 \%$ (20.2\%) from ZFP to IFMP (Table S2). Regarding fire intensity, in Xerente and for the WFS, both NFP and IFMP displayed lower FRPp90 values than ZFP, when fires are much more intense (with a heavier right tail than that of IFMP). The increase in fire intensity during the zero-fire period is also notable in Araguaia during the WFS. In Xerente (Araguaia), FRPp90 increased from 96 MW (157 MW) in NFP to $106 \mathrm{MW}$ (167 MW) in ZFP and showed a reduction of up to $105 \mathrm{MW}$ (150 MW) in IFMP. This represents a slight reduction in extreme FRP values due to the IFM program compared with the zero-fire period in Xerente. However, in Araguaia, this reduction reached 10.3\% (Table S2). During the WFS, we observed an increase of $7.7 \%$ and $22 \%$ in median values of $\mathrm{PM}_{2.5}$ between ZFP and IFMP in Xerente and Araguaia. However, extreme $\mathrm{PM}_{2.5}$ emissions values increased from NFP to ZFP (16.3\% and 10.1\%) and decreased to IFMP (10\% and $18.2 \%)$ in Xerente and Araguaia.

In IFMP, not only did the WFS burn at a lower intensity than during ZFP, but extreme BA and emissions tended to be lower. Relative changes between phases are visually confirmed based on 1000 samples generated by the bootstrapping approach. Based on each sample (for instance, FRP values for IFMP), we create new 1000 samples using a bootstrapping approach, then for each one of the 1000 samples, we compute percentiles 10th to 90th, in steps of 10, in a way to calculate confidence intervals for bootstrapped samples [86]. Results of this analysis are provided in Supplementary Material. These boxplots show values of BA (Figure S3), FRP (Figure S4), and PM 2.5 (Figure S5) percentiles 10th to 90th for Araguaia and Xerente and for the entire year, MFS and WFS for each group of 1000 samples generated by bootstrapping approach. Values for each phase are sequentially depicted for each percentile from 10th to 90th. For the WFS, these analyses reveal that there are no overlaps between the medians of each phase. In general, there is an increase in BA, FRP, and $\mathrm{PM}_{2.5}$ from NFP to ZFP in the higher percentiles, followed by a conspicuous decrease from ZFP to IFMP. This behavior indicates that changes between these phases are statistically significant.

Finally, we found clear changes in spatial and temporal patterns of the recurrence of large fires during the three phases in both regions (Figure 5 and Table S3). High recurrence presents substantial spatial heterogeneity among the three phases, accounting for $17.2 \%$ $(10.9 \%)$ of the region's area during NFP, increasing to $23.9 \%(22 \%)$ in ZFP, and considerably decreasing up to $6.2 \%(11.4 \%$ ) during IFMP in Xerente (Araguaia) (Figure $5 \mathrm{c}, \mathrm{d}$ ). By contrast, zero- and low-recurrence areas decreased from NFP (82.8\% in Xerente; $89 \%$ in Araguaia) to ZFP (76.1\% in Xerente; 78\% in Araguaia), growing up to $93.8 \%$ (88.5\%) in Xerente (Araguaia) in IFMP. The most pronounced change, owing to the IFM program implementation (IFMP) when compared with ZFP, was observed in Xerente, where the area affected by low (high) recurrence increased (decreased) 23.3\% (74.1\%). In Araguaia, the area affected by low (high) recurrence increased (decreased) 13.5\% (48.2\%) from ZFP to IFMP. This represents a reduction of $74.1 \%(48.2 \%)$ in the area affected by high recurrence in Xerente (Araguaia) from ZFP to IFMP (Table S3).

Fires during each phase have different seasonal cycles for all scar sizes (Figure 6). Table S4 presents the modal months of high fire activity, highlighting the first and second highest peak in the case of bimodal patterns. Fire scar distribution varies within each phase (Figure 6, Table S4), especially in Araguaia. In Xerente, with fewer scars, the different patterns between phases were not clear. However, we can see a flare on fire distribution on very small scars on IFMP compared with ZFP (Figure 6a-c, Table S4a). We observed a slight decrease on very small and small scars with a bimodal pattern, where the higher values are concentrated in July and September (Figure 6a). Medium and large scar numbers have similar values in the three phases, with higher values in mid-August and September (Figure 6e-g, Table S4a). In Araguaia, very small and small scar numbers have the lowest frequency in IFMP, showing a bimodal pattern, where the highest values are concentrated in July and September for very small scars (Figure 6b, Table S4b) and in July for small scars (Figure 6d, Table S4b), contrasting with the peak in September during the ZFP. The bimodal pattern is also observed for medium and large fires (Figure 6f,h, Table S4b). Medium scars 
have a displacement from mid-August (NFP) to mid-September (ZFP), shifting to July (highest first peak) during IFMP. Large scars showed an accentuated shift during IFMP, with the highest peaks in July and September, contrasting with the August peak during the ZFP.
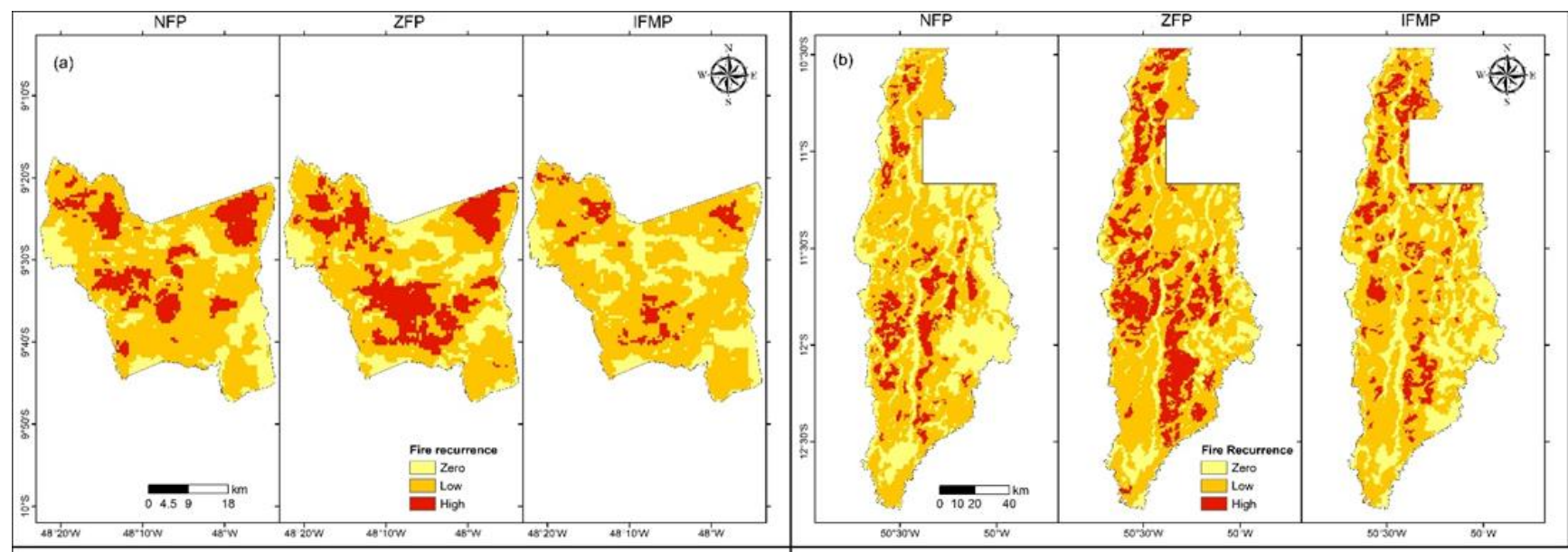

(c)

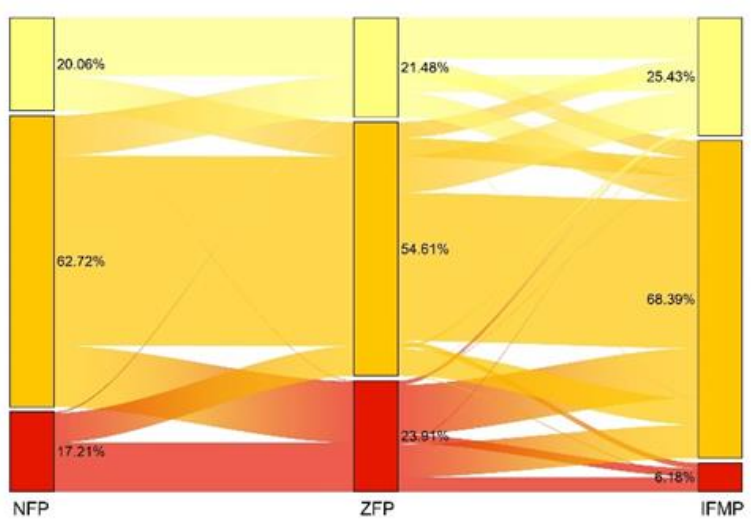

(d)

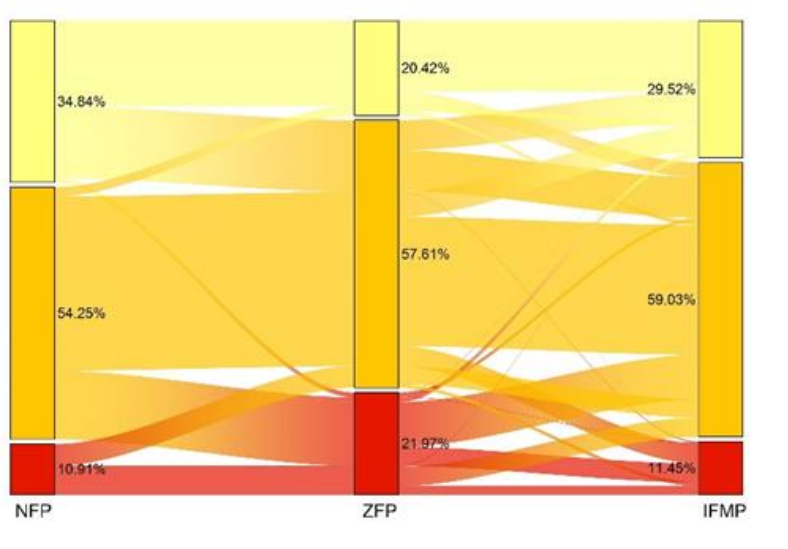

Figure 5. Average fire recurrence for large scars during the three fire policy phases in Xerente (left column) and Araguaia (right column). Panels (a,b) show the spatial variation between the three phases. Panels (c,d) depict alluvial diagrams repreScheme 0 ( $\leq 0.6$ fire occurrence per year, orange) and high frequency $(>0.6$ fire occurrence per year, red).

Accordingly, fire seasonality changed between phases, specifically in Araguaia, where the scars are more distributed throughout the year, allowing better resources to prevent and combat wildfires. 

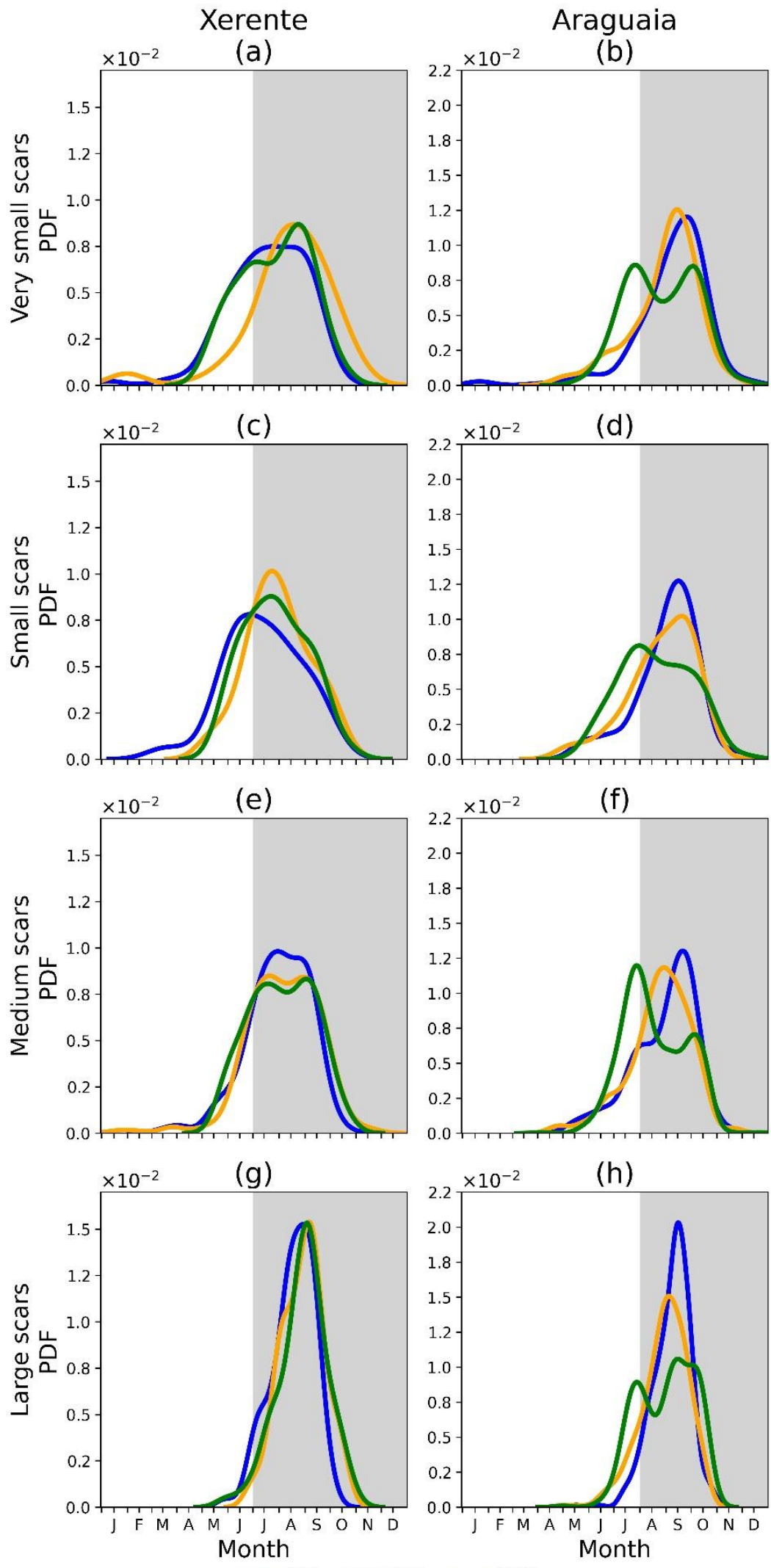

Figure 6. Seasonal distribution of fire scars from 2003 to 2018 per size class in Xerente (left column) and Araguaia (right column): very small (VS, a,b), small (S, c,d), medium (M, e,f) and large (L, $\mathbf{g}, \mathbf{h})$ for the three phases. The grey column represents WFS. 


\section{Discussion}

\subsection{Evaluating $P B s$}

The main focus of our research is to evaluate whether PBs contribute to reaching the main goals of the IFM program [6,44]. Our findings reveal that PB in both IT contributed to (i) the average rise of $\mathrm{BA}$ and $\mathrm{SN}$ from management season and the decrease from extremes wildfires season; (ii) lower-intensity and smaller-extension extreme wildfires; (iii) lower emissions during extreme events; (iv) the increase of low-fire-recurrence regions; and (v) changes in fire seasonality, decreasing extreme wildfires in the late-dry-season. By revealing changes in fire patterns across different fire policy phases, our results reinforce the PB concept, within the IFM program, as an essential strategy to properly reduce emissions without compromising local biodiversity and control fuel loads in the WFS to prevent large and severe wildfire occurrences $[4,42,82]$. The observed changes in the fire regime due to the implementation of $\mathrm{PB}$, namely, reduced and a more fragmented BA with more scars in the WFS, are in agreement with other studies that analyzed PB programs worldwide $[13,18,87-89]$. In both ITs, the total BA decreased (increased) in the WFS (MFS) with IFM, supporting PB as a potent land management tool to reduce the large extension and number of wildfires or unplanned fires. The reduction in fire intensity and $\mathrm{PM}_{2.5}$ extreme values in the first four years of the IFM program and the decrease in high-recurrence areas are promising and crucial for fire-prone ecosystem maintenance. Low-intensity fires have low impacts on fire-resistant vegetation and help create mosaics in the landscape with different fire histories, fundamental to conserve the biodiversity in tropical savannas, and the ecosystem services linked to fire events [42]. Similarly, other studies have shown $\mathrm{CO}_{2}$ emissions reductions in the western United States (18-25\%) [90] and Australia (38\%) [8] linked to PB actions.

The distribution of scar size class showed a distinct dynamic within both study regions and seasons. In the MFS, Xerente shows a predominance of medium scars that account for most of the total BA, whereas in Araguaia, few large fires correspond to most of the BA in this season. In the WFS, few large fires represent the greatest total BA for both ITs, as observed by other areas over the Cerrado biome $[50,80,81,91]$ and are similar to those of tropical savannas in Africa and Australia [31,32,34,92,93]. Those patterns are in agreement with a recent study [50], which showed that few scars (7.1\%) were responsible for more than $71.8 \%$ of the total BA in the last 20 years in Bananal ecoregion, where Araguaia and Xerente are located.

Previous studies have discussed the long-term fire regime patterns over Cerrado [50,82], however, few considered the role of the fire management policies in these patterns. Most current information was obtained from in situ studies that cover relatively small portions and use simple statistics or categorical measures of fire. Despite differences in study regions and datasets/treatment characteristics, our results about the constraints of key fire characteristics (i.e., intensity and area burned) under WFS and the shifts of fire season were consistent with those previous works, which found that PB successfully alters fire behavior relative to untreated areas in Cerrado. For instance, Mistry et al. [94] explored the traditional use of fire as a management tool in the Krahô IT and verified that fires for various reasons throughout the dry season produced a mosaic of burned and unburned patches in the landscape. Schmidt et al. $[6,44]$ showed that the fire season changed over protected areas with a reduction of around $50 \%$ in late dry fires over the program's first three years. Falleiro et al. [46] verified a $17 \%$ of BA reduction in comparison over 15 ITs that have IFM plans. Alvarado et al. [95] compared protected areas over Brazil and South Africa and observed that active fire suppression did not alter the total BA but modified the seasonal fire distribution. Batista et al. [41] observed the fire regime in Canastra National Park, and found the wildfires in the late-dry-season more severe and extensive, supporting the necessity of PB to manage fire-resistant Cerrado ecosystems. Eloy et al. [43] analyzed the two first years of the IFM program in the Jalapão region, recognizing a BA reduction of (4-21\%) in the late-dry-season, revealing that burning mosaics can be beneficial to wildfire prevention. Finally, Melo et al. [45] investigated nine ITs in northeastern Cerrado regarding 
fire recurrence patterns, fire-dependent characteristics of Cerrado, and the tendency to extend the BA due to climate impacts.

Increases in the effectiveness of wildfire suppression are expected with PB [96], and investments in IFM are effective for reducing BA [40]. However, Araguaia and Xerente territories are embedded in anthropogenic land covers (as shown in Figure 1), including mainly pastures and agriculture fields, where burning is a routine procedure [43]. This fact highlights the importance of surrounding conservation plans for those protected areas. An important aspect of fire management in the Brazilian savanna is that IFM is still only implemented in federal PA, including ITs, and wildfires during the WFS are still very common in most remnant vegetation in the Cerrado [50]. In private areas, fire policies are badly implemented, with bureaucratic burning permits that are usually not granted to (or even demanded by) farmers who commonly used illegal, and therefore untanned fires to manage their lands, resulting in frequent wildfires, which can even reach PAs and ITs [17]. This fact highlights the importance of a national fire management policy implementation that allows for the effective use of prescribed and controlled fires over different land ownership contexts. Such a national policy has been under discussion in the Brazilian parliament since 2018 (Law project 11.276/2018), but it has not advanced in the past years due to an environmentally unfriendly governmental agenda.

Finally, we observed through FWI that a decrease in precipitation combined with high temperatures and low humidity over the two regions contributes to a positive trend of fire risk, especially in the last years of the temporal series. These climate variations lead to a decrease in soil moisture, affecting vegetation flammability and creating ideal conditions for widespread biomass burning $[18,92]$. Worldwide, climate change has been increasing the likelihood of aggravated fire seasons and higher BA, and Cerrado is no exception [97]. Until the end of this century, an increasing potential fire weather risk to the Cerrado now seems almost inevitable due to global warming [49]. Based on our results, in the presence of extensive prescribed fire management, dry and hot trends do not inevitably increase wildfire activity. Accordingly, we argue that the impact of wildfires can still be potentially reduced if effective fire management policies, including PB, continue to be implemented over the coming decades.

\subsection{Limitations of Current Datasets}

Although the present study addressed only two indigenous territories in Cerrado, the approach could be adapted and applied in a variety of regions, as it is the first to consider other factors of the fire regime besides BA or active fire counts, such as frequency, fire intensity, seasonality, and emissions, to evaluate PB effectiveness.

It is noteworthy that we cannot distinguish the fire origin with limited PB information and BA product size mapping ( $>25 \mathrm{ha}$ ) due to sensor limitation [27]. PB fires are low-intensity and usually small to keep them under control, making satellite detection difficult [98], even by medium-spatial-resolution satellite imagery such as Landsat [99]. In addition, the frequent presence of clouds in the tropical region during the active burn season obscures the satellites' view [100], contributing to large uncertainty in estimating the BA of those small fires [101,102]. This is especially true for MCD64 BA detections, where accuracy is limited in regions with small and fragmented scars [103-107]. In the Brazilian savannas, omission errors were also reported, in particular, for very small scars (less than $100 \mathrm{ha}$ [ [82]. Indeed, scar size is the largest driver of accuracy across all land covers over Cerrado [91].

There are several challenges in the current PB database in Cerrado, which probably impact some of our analyses. First, PBs were recently implemented in Brazil; thus, a longterm time series is not yet available, in contrast to other countries [89]. Second, there is an absence of systematic information regarding the extent of $\mathrm{PB}$ and the perimeters in both ITs, enabling a proper distinction between management and wildfires within satellite-derived databases. Hence, an official, accurate, and comprehensive PB database, including fire extension, perimeter, and duration, could be important to help understand and better plan 
fire management regimes. For that to be possible, such an endeavor requires high and continuous investments in equipment, human resources, and technology. Accordingly, sufficient funding should be assigned to IFM, looking forward to generating more effective, systematic, and long-lasting results on controlling wildfire's destructive impact.

Finally, the analysis presented here is founded on the historical variability of fire patterns and the evolution of $\mathrm{PB}$ activities and climate trends, not taking into account other possible fire drivers. As stated early $[7,108]$, it is unrealistic to expect that PB alone will reduce the occurrence of wildfires, and for this reason, further analysis should be undertaken in terms of other drivers of fire change. The effectiveness of PB in the long run is a challenging task, and the consideration of the dynamic influence of social and economic change is required $[7,108]$. For instance, fire dynamics in both regions are affected by several other factors rather than by management, such as land ownership conflicts, land-use changes, fires from surrounding unprotected areas, and the weather conditions at the time of the fire occurrence [44]. Moreover, variations in fire suppression efforts and in the availability and quality of equipment used may also introduce additional influence on the observed results obtained here. In addition, anthropogenic pressures from surrounding unprotected areas are known to be responsible for fire occurrence in protected areas in Cerrado, with human negligence, high road availability, and expansion of agricultural and pasture fields [109]. However, this confounding factor of fires from surrounding unprotected areas was not considered here. Therefore, although challenging, the interactive effects of such variables and prescribed burning should be taken into account in future studies. Nevertheless, we are confident that our results provide novel and useful insights to fill current gaps in the knowledge about PB effectiveness in Cerrado.

\section{Final Remarks}

Previous studies have shown that fire management practices, including PB, should be employed to further protect fire-prone ecosystems by creating burning mosaics-a strategy already used in West Africa, Australia, and by the US forest services-to limit the risk of large fire events [50,110-112]. Brazil was one of the last countries with tropical savannas to adopt an effective fire management policy. This resistance to change from a zero-fire policy to the presently implemented IFM program can be explained by a historical colonial legacy $[6,16,17,55]$, but also by considerable uncertainty related to the effects of different fire regimes on very diverse ecosystems [4,42]. Since local communities are deeply involved in fire management activities and in a landscape where fire ignitions are predominantly human, the exchange of knowledge among environmental managers, researchers, and these traditional communities is essential to develop strategies to better conserve tropical savannas [108,113]. Associated with other ecological variables, our results may also provide crucial insights about regional ecological impacts and the effects of differing fire-management practices within each region, thus supporting the development of locally adjusted fire-management practices.

Based on our results, we believe that the IFM program can potentially reduce wildfires and disseminate successful PB applications to other areas, creating a more reliable, unique, and continuous national planned fires and wildfires database to serve other fire management plans. Future work should devote more attention to the socioeconomic, biodiversity, and emissions implications of $\mathrm{PB}$ and, to this end, expand to encompass long-term experiments and monitored management programs [114]. Thus, we expect that our results could be useful to inform and support a better allocation of financial and human resources in managing fires as well as in decision-making strategies under current and future conditions.

Supplementary Materials: The following are available online at https: / www.mdpi.com/article/ 10.3390 / fire4030056/s1, Figure S1: Prescribed burning (PB) over the Xerente IT between 2015 and 2018. Basemap: Google Satellite; Figure S2: Same as Figure S1, but for Araguaia; Figure S3: Boxplot showing values of burned area (BA) percentiles 10th to 90th for Araguaia (left columns) and Xerente (right columns) and for the entire years (upper row), MFS (middle row) and WFS (bottom row) 
for each group of 1000 samples generated by bootstrapping approach. Values for Phases 1, 2 and 3 are sequentially depicted for each percentile from 10th to 90 th. The medians are represented by black circles; Figure S4: Same as in Figure S3, but for FRP; Figure S5: Same as in Figure S3, but for PM2.5. Table S1: Relative difference (\%) of the percentile 50th and 90th (in parenthesis) from annual accumulated burned area (BA) and total scar number (SN)(according to Figure 3) between NFP and ZFP, and between ZFP and IFM in Xerente (a) and Araguaia (b) for each fire season: management fire season (MFS) and wildfires season (WFS); Table S2: Relative difference (\%) of the percentile 50th and 90th (in parenthesis) from burned area (BA) of large scars, fire radiative power (FRP) and pyrogenic emission (PM2.5) distribution (Figure 4) between NFP and 2 and between ZFP and 3 in Xerente (a) and Araguaia (b) for wildfires season (WFS); Table S3: The proportion of pixels (i.e., area) in each fire recurrence class: zero, low ( $\leq 0.6$ fire occurrence per year) and high $(>0.6$ fire occurrence per year) in Xerente (a) and Araguaia (b), according to Figure 5; Table S4: Modal month in each class for all three phases on Xerente (a) and Araguaia (b), according to Figure 6.

Author Contributions: Conceptualization, F.L.M.S., J.N. and R.L.; methodology, F.L.M.S., J.N. and R.L.; software, F.L.M.S.; validation, F.L.M.S., J.N., R.A.F.d.S., R.M.F., I.B.S. and R.L.; formal analysis, F.L.M.S., J.N., R.A.F.d.S., R.M.F., I.B.S. and R.L.; investigation, F.L.M.S., J.N. and R.L.; resources, F.L.M.S., J.N. and R.L.; data curation, F.L.M.S.; writing—original draft preparation, F.L.M.S., J.N. and R.L.; writing-review and editing, F.L.M.S., J.N., R.A.F.d.S., R.M.F., I.B.S. and R.L.; visualization, F.L.M.S., J.N. and R.L.; supervision, J.N. and R.L.; project administration, R.L; funding acquisition, R.L. All authors have read and agreed to the published version of the manuscript.

Funding: This research was developed under the scope of the Project Andura [CNPq grant number 441971/2018-0] and partially supported by World Wide Fund for Nature (WWF-Brasil); F.L.M.S. was early supported by CNPq [grant number 381461/2018-1] and is financed by the Coordenação de Aperfeiçoamento de Pessoal de Nível Superior-Brasil (CAPES)-Finance Code 001 [grant number 88887.498119/2020-00]; J.N. was supported by 'Women in Research'-fellowship program, WWU Münster; I.B.S. was supported by CNPq [grant number 441951/2018-0]; R.L. was supported by CNPq [grant number 305159/2018-6] and FAPERJ [grant number E26/202.714/2019]; FCT supports CEF [project UIDB/00239/2020] and IDL [project UIDB/50019/2020].

Acknowledgments: The authors would like to thank Niels Andela for providing Global Fire Atlas data from 2017-2018. We acknowledge the use of data and/or imagery from NASA's Fire Information for Resource Management System (FIRMS) (https: / / earthdata.nasa.gov / firms accessed on 3 July 2021), part of NASA's Earth Observing System Data and Information System (EOSDIS). Finally, we thank Carlos DaCamara for helping with statistical approaches.

Conflicts of Interest: The authors declare no conflict of interest.

\section{References}

1. Van der Werf, G.R.; Randerson, J.T.; Giglio, L.; van Leeuwen, T.T.; Chen, Y.; Rogers, B.M.; Mu, M.; van Marle, M.J.E.; Morton, D.C.; Collatz, G.J.; et al. Global fire emissions estimates during 1997-2016. Earth Syst. Sci. Data 2017, 9, 697-720. [CrossRef]

2. Bowman, D.M.J.S.; Kolden, C.A.; Abatzoglou, J.T.; Johnston, F.H.; Van Der Werf, G.R.; Flannigan, M. Vegetation fires in the Anthropocene. Nat. Rev. Earth Environ. 2020, 1, 500-515. [CrossRef]

3. Lipsett-Moore, G.J.; Wolff, N.H.; Game, E.T. Emissions mitigation opportunities for savanna countries from early dry season fire management. Nat. Commun. 2018, 9, 2247. [CrossRef]

4. Gillson, L.; Whitlock, C.; Humphrey, G. Resilience and fire management in the Anthropocene. Ecol. Soc. 2019, 24, 14. [CrossRef]

5. Ryan, K.C.; Knapp, E.E.; Varner, J.M. Prescribed fire in North American forests and woodlands: History, current practice, and challenges. Front. Ecol. Environ. 2013, 11. [CrossRef]

6. Schmidt, I.B.; Moura, L.C.; Ferreira, M.C.; Eloy, L.; Sampaio, A.B.; Dias, P.A.; Berlinck, C.N. Fire management in the Brazilian savanna: First steps and the way forward. J. Appl. Ecol. 2018, 55, 2094-2101. [CrossRef]

7. Penman, T.D.; Christie, F.J.; Andersen, A.N.; Bradstock, R.A.; Cary, G.J.; Henderson, M.K.; Price, O.; Tran, C.; Wardle, G.M.; Williams, R.J.; et al. Prescribed burning: How can it work to conserve the things we value? Int. J. Wildland Fire 2011, 20, 721-733. [CrossRef]

8. Russell-Smith, J.; Cook, G.D.; Cooke, P.M.; Edwards, A.C.; Lendrum, M.; Meyer, C.; Whitehead, P.J. Managing fire regimes in north Australian savannas: Applying Aboriginal approaches to contemporary global problems. Front. Ecol. Environ. 2013, 11, e55-e63. [CrossRef]

9. Eskander, S.M.S.U.; Fankhauser, S. Reduction in greenhouse gas emissions from national climate legislation. Nat. Clim. Chang. 2020, 10, 750-756. [CrossRef] 
10. Russell-Smith, J.; Monagle, C.; Jacobsohn, M.; Beatty, R.L.; Bilbao, B.; Millán, A.; Vessuri, H.; Sánchez-Rose, I. Can savanna burning projects deliver measurable greenhouse emissions reductions and sustainable livelihood opportunities in fire-prone settings? Clim. Chang. 2017, 140, 47-61. [CrossRef]

11. Mueller, E.; Skowronski, N.; Clark, K.; Kremens, R.; Gallagher, M.; Thomas, J.; Houssamia, M.E.; Filkov, A.; Butler, B.; Hom, J.; et al. An experimental approach to the evaluation of prescribed fire behavior. In Advances in Forest Fire Research; Imprensa da Universidade de Coimbra: Coimbra, Portugal, 2014; pp. 41-53.

12. Hunter, M.E.; Robles, M.D. Tamm review: The effects of prescribed fire on wildfire regimes and impacts: A framework for comparison. For. Ecol. Manag. 2020, 475, 118435. [CrossRef]

13. Podschwit, H.; Miller, C.; Alvarado, E. Spatiotemporal Prescribed Fire Patterns in Washington State, USA. Fire 2021, 4, 19. [CrossRef]

14. Davim, D.A.; Rossa, C.G.; Fernandes, P.M. Survival of prescribed burning treatments to wildfire in Portugal. For. Ecol. Manag. 2021, 493, 119250. [CrossRef]

15. Costa, Y.T.; Thomaz, E.L. Management, sustainability and research perspective of prescribed fires in tropical parks. Curr. Opin. Environ. Sci. Health 2021, 22, 100257. [CrossRef]

16. Durigan, G. Zero-fire: Not possible nor desirable in the Cerrado of Brazil. Flora 2020, 268, 151612. [CrossRef]

17. Durigan, G.; Ratter, J.A. The need for a consistent fire policy for Cerrado conservation. J. Appl. Ecol. 2016, 53, 11-15. [CrossRef]

18. Murphy, B.P.; Cochrane, M.A.; Russell-Smith, J. Prescribed burning protects endangered tropical heathlands of the Arnhem Plateau, northern Australia. J. Appl. Ecol. 2015, 52, 980-991. [CrossRef]

19. Archibald, S. Managing the human component of fire regimes: Lessons from Africa. Philos. Trans. R. Soc. B Biol. Sci. 2016, 371, 20150346. [CrossRef]

20. Silveira, L.; Henrique, F.; Rodrigues, F.H.G.; Jácomo, A.T.D.A.; Filho, J.A.F.D. Impact of wildfires on the megafauna of Emas National Park, central Brazil. Oryx 1999, 33, 108-114. [CrossRef]

21. Freeman, J.; Kobziar, L.; Rose, E.W.; Cropper, W. A critique of the historical-fire-regime concept in conservation. Conserv. Biol. 2017, 31, 976-985. [CrossRef] [PubMed]

22. Sletto, B. The Knowledge that Counts: Institutional Identities, Policy Science, and the Conflict Over Fire Management in the Gran Sabana, Venezuela. World Dev. 2008, 36, 1938-1955. [CrossRef]

23. Matos, R.M.P.; Aguiar, L.L.L.; Martins, P.T.D.A. Ocorrência de fogo no Parque Nacional da Chapada dos Veadeiros, Goiás, Brasil: Histórico recente no contexto da sua ampliação. GeoTextos 2020, 16. [CrossRef]

24. Abreu, R.C.R.; Hoffmann, W.A.; Vasconcelos, H.L.; Pilon, N.A.; Rossatto, D.R.; Durigan, G. The biodiversity cost of carbon sequestration in tropical savanna. Sci. Adv. 2017, 3, e1701284. [CrossRef]

25. Eloy, L.; Bilbao, B.A.; Mistry, J.; Schmidt, I.B. From fire suppression to fire management: Advances and resistances to changes in fire policy in the savannas of Brazil and Venezuela. Geogr. J. 2018, 185, 10-22. [CrossRef]

26. Schmidt, I.B.; Eloy, L. Fire regime in the Brazilian Savanna: Recent changes, policy and management. Flora 2020, $268,151613$. [CrossRef]

27. Giglio, L.; Schroeder, W.; Justice, C.O. The collection 6 MODIS active fire detection algorithm and fire products. Remote. Sens. Environ. 2016, 178, 31-41. [CrossRef]

28. Balch, J.; Denis, L.S.; Mahood, A.; Mietkiewicz, N.; Williams, T.; McGlinchy, J.; Cook, M. FIRED (Fire Events Delineation): An Open, Flexible Algorithm and Database of US Fire Events Derived from the MODIS Burned Area Product (2001-2019). Remote. Sens. 2020, 12, 3498. [CrossRef]

29. Oom, D.; Silva, P.C.; Bistinas, I.; Pereira, J.M.C. Highlighting Biome-Specific Sensitivity of Fire Size Distributions to Time-Gap Parameter Using a New Algorithm for Fire Event Individuation. Remote. Sens. 2016, 8, 663. [CrossRef]

30. Archibald, S.; Roy, D.P. Identifying individual fires from satellite-derived burned area data. In Proceedings of the 2009 IEEE International Geoscience and Remote Sensing Symposium, Cape Town, South Africa, 12-17 July 2009; Volume 3, pp. III-160-III-163.

31. Andela, N.; Morton, D.C.; Giglio, L.; Paugam, R.; Chen, Y.; Hantson, S.; van der Werf, G.R.; Randerson, J.T. The Global Fire Atlas of individual fire size, duration, speed and direction. Earth Syst. Sci. Data 2019, 11, 529-552. [CrossRef]

32. Laurent, P.; Mouillot, F.; Yue, C.; Ciais, P.; Moreno, M.V.; Nogueira, J.M.P. FRY, a global database of fire patch functional traits derived from space-borne burned area products. Sci. Data 2018, 5, 180132. [CrossRef]

33. Nogueira, J.M.P.; Ruffault, J.; Chuvieco, E.; Mouillot, F. Can We Go Beyond Burned Area in the Assessment of Global Remote Sensing Products with Fire Patch Metrics? Remote. Sens. 2016, 9, 7. [CrossRef]

34. Hantson, S.; Pueyo, S.; Chuvieco, E. Global fire size distribution is driven by human impact and climate. Glob. Ecol. Biogeogr. 2014, 24, 77-86. [CrossRef]

35. Artés, T.; Oom, D.; De Rigo, D.; Durrant, T.H.; Maianti, P.; Libertà, G.; San-Miguel-Ayanz, J. A global wildfire dataset for the analysis of fire regimes and fire behaviour. Sci. Data 2019, 6, 1-11. [CrossRef]

36. Campagnolo, M.L.; Oom, D.; Padilla, M.; Pereira, J.M.C. A patch-based algorithm for global and daily burned area mapping. Remote. Sens. Environ. 2019, 232, 111288. [CrossRef]

37. Fernandes, P.M. Empirical Support for the Use of Prescribed Burning as a Fuel Treatment. Curr. For. Rep. 2015, 1, 118-127. [CrossRef]

38. Vernooij, R.; Giongo, M.; Borges, M.A.; Costa, M.M.; Barradas, A.C.S.; van der Werf, G.R. Intraseasonal variability of greenhouse gas emission factors from biomass burning in the Brazilian Cerrado. Biogeosciences 2021, 18, 1375-1393. [CrossRef] 
39. Berlinck, C.N.; Batista, E.K.L. Good fire, bad fire: It depends on who burns. Flora 2020, 268, 151610. [CrossRef]

40. Oliveira, A.; Soares-Filho, B.; Oliveira, U.; Van der Hoff, R.; Carvalho-Ribeiro, S.; Scheepers, L.; Vargas, B.; Rajão, R. Costs and effectiveness of public and private fire management programs in the Brazilian Amazon and Cerrado. For. Policy Econ. 2021, 127, 102447. [CrossRef]

41. Batista, E.K.L.; Russell-Smith, J.; França, H.; Côrtes-Figueira, J.E. An evaluation of contemporary savanna fire regimes in the Canastra National Park, Brazil: Outcomes of fire suppression policies. J. Environ. Manag. 2018, 205, 40-49. [CrossRef]

42. Pivello, V.R.; Vieira, I.; Christianini, A.V.; Ribeiro, D.B.; da Silva Menezes, L.; Berlinck, C.N.; Melo, F.P.; Marengo, J.A.; Tornquist, C.G.; Tomas, W.M.; et al. Understanding Brazil's catastrophic fires: Causes, consequences and policy needed to prevent future tragedies. Perspect. Ecol. Conserv. 2021, 19, 233-255. [CrossRef]

43. Eloy, L.; Schmidt, I.B.; Borges, S.L.; Ferreira, M.C.; Dos Santos, T.A. Seasonal fire management by traditional cattle ranchers prevents the spread of wildfire in the Brazilian Cerrado. Ambio 2018, 48, 890-899. [CrossRef]

44. Schmidt, I.B.; Fonseca, C.B.; Ferreira, M.C.; Sato, M.N. Implementação do programa piloto de manejo integrado do fogo em três unidades de conservação do Cerrado. Biodivers. Bras. BioBrasil 2016, 2, 55-70. [CrossRef]

45. Melo, P.; Sparacino, J.; Argibay, D.; Júnior, V.S.; Barros, R.; Espindola, G. Assessing Wildfire Regimes in Indigenous Lands of the Brazilian Savannah-Like Cerrado. Fire 2021, 4, 34. [CrossRef]

46. De Moraes Falleiro, R.; Steil, L.; de Oliveira, M.S.; Lando, I.; de Machado, L.O.R.; Cunha, A.M.C.; Zacharias, G.C. Histórico, Avaliação, Oportunidades e Desafios do Manejo Integrado do Fogo nas Terras Indígenas Brasileiras. Biodivers. Bras. BioBrasil 2021, 2, 75-98. [CrossRef]

47. Ribeiro, J.F.; Walter, B.M.T. Fitofisionomias do Bioma Cerrado. In Cerrado: Ambiente e Flora; Sano, S.M., Almeida, S.P.d., Eds.; EMBRAPA-CPAC: Planaltina, Brazil, 1998; pp. 89-166.

48. Ratter, J.A.; Ribeiro, J.F.; Bridgewater, S. The Brazilian Cerrado Vegetation and Threats to its Biodiversity. Ann. Bot. 1997, 80, 223-230. [CrossRef]

49. Silva, P.S.; Bastos, A.; Libonati, R.; Rodrigues, J.A.; DaCamara, C.C. Impacts of the $1.5^{\circ} \mathrm{C}$ global warming target on future burned area in the Brazilian Cerrado. For. Ecol. Manag. 2019, 446, 193-203. [CrossRef]

50. Silva, P.S.; Nogueira, J.; Rodrigues, J.A.; Santos, F.L.M.; Pereira, J.M.C.; Da Camara, C.C.; Daldegan, G.A.; Pereira, A.A.; Peres, L.F.; Schmidt, I.B.; et al. Putting fire on the map of Brazilian savanna ecoregions. J. Environ. Manag. 2021, 296, 113098. [CrossRef]

51. Fundação Nacional do Índio Terras Indígenas. Available online: http:/ / www.funai.gov.br/index.php/indios-no-brasil/terrasindigenas (accessed on 11 June 2021).

52. Roldão, A.D.F.; Ferreira, V.D.O. Climatologia do Estado do Tocantins_Brasil. Caderno Geografia 2019, 29, 1161-1181. [CrossRef]

53. Instituto Socioambiental Terra Indígena Xerente / Terras Indígenas no Brasil. Available online: https://terrasindigenas.org.br/ptbr/terras-indigenas/3907 (accessed on 11 June 2021).

54. Instituto Socioambiental Parque Indígena Araguaia I Terras Indígenas no Brasil. Available online: https://terrasindigenas.org.br/ pt-br/terras-indigenas/3592 (accessed on 11 June 2021).

55. Pivello, V.R. The Use of Fire in the Cerrado and Amazonian Rainforests of Brazil: Past and Present. Fire Ecol. 2011, 7, 24-39. [CrossRef]

56. Instituto Socioambiental Xerente-Povos Indígenas No Brasil. Available online: https://pib.socioambiental.org/pt/Povo:Xerente (accessed on 11 June 2021).

57. Eloy, L.; Hecht, S.; Steward, A.; Mistry, J. Firing up: Policy, politics and polemics under new and old burning regimes. Geogr. J. 2019, 185, 2-9. [CrossRef]

58. Mistry, J.; Schmidt, I.B.; Eloy, L.; Bilbao, B. New perspectives in fire management in South American savannas: The importance of intercultural governance. Ambio 2019, 48, 172-179. [CrossRef]

59. Giglio, L.; Csiszar, I.; Justice, C.O. Global distribution and seasonality of active fires as observed with the Terra and Aqua Moderate Resolution Imaging Spectroradiometer (MODIS) sensors. J. Geophys. Res. Space Phys. 2006, 111. [CrossRef]

60. Di Giuseppe, F.; Pappenberger, F.; Wetterhall, F.; Krzeminski, B.; Camia, A.; Libertá, G.; Miguel, J.S. The Potential Predictability of Fire Danger Provided by Numerical Weather Prediction. J. Appl. Meteorol. Clim. 2016, 55, 2469-2491. [CrossRef]

61. Inness, A.; Ades, M.; Agustí-Panareda, A.; Barré, J.; Benedictow, A.; Blechschmidt, A.-M.; Dominguez, J.J.; Engelen, R.; Eskes, H.; Flemming, J.; et al. The CAMS reanalysis of atmospheric composition. Atmospheric Chem. Phys. Discuss. 2019, 19, 3515-3556. [CrossRef]

62. Giglio, L.; Boschetti, L.; Roy, D.P.; Humber, M.L.; Justice, C.O. The Collection 6 MODIS burned area mapping algorithm and product. Remote. Sens. Environ. 2018, 217, 72-85. [CrossRef]

63. Schroeder, W.; Csiszar, I.; Giglio, L.; Schmidt, C.C. On the use of fire radiative power, area, and temperature estimates to characterize biomass burning via moderate to coarse spatial resolution remote sensing data in the Brazilian Amazon. J. Geophys. Res. Space Phys. 2010, 115, D21121. [CrossRef]

64. Giglio, L. Characterization of the tropical diurnal fire cycle using VIRS and MODIS observations. Remote. Sens. Environ. 2007, 108, 407-421. [CrossRef]

65. Di Giuseppe, F.; Rémy, S.; Pappenberger, F.; Wetterhall, F. Using the Fire Weather Index (FWI) to improve the estimation of fire emissions from fire radiative power (FRP) observations. Atmos. Chem. Phys. Discuss. 2018, 18, 5359-5370. [CrossRef]

66. Nogueira, J.M.P.; Rambal, S.; Barbosa, J.P.R.A.D.; Mouillot, F. Spatial Pattern of the Seasonal Drought/Burned Area Relationship across Brazilian Biomes: Sensitivity to Drought Metrics and Global Remote-Sensing Fire Products. Climate 2017, 5, 42. [CrossRef] 
67. Pinto, M.M.; Dacamara, C.C.; Trigo, I.F.; Trigo, R.M.; Turkman, K.F. Fire danger rating over Mediterranean Europe based on fire radiative power derived from Meteosat. Nat. Hazards Earth Syst. Sci. 2018, 18, 515-529. [CrossRef]

68. Taylor, S.W.; Alexander, M.E. Science, technology, and human factors in fire danger rating: The Canadian experience. Int. J. Wildland Fire 2006, 15, 121-135. [CrossRef]

69. Chow, J.C.; Watson, J.; Lowenthal, D.H.; Chen, L.-W.A.; Motallebi, N. PM2.5 source profiles for black and organic carbon emission inventories. Atmos. Environ. 2011, 45, 5407-5414. [CrossRef]

70. Niels Andela Fire Atlas-Global Fire Emissions Database. Available online: https://www.globalfiredata.org/fireatlas.html (accessed on 15 June 2021).

71. Fire Information For Resource Management System MODIS/Aqua+Terra Thermal Anomalies/Fire Locations 1 km (MCD14ML) V006 and V0061 Standard (Vector data) distributed by LANCE FIRMS. Available online: https://earthdata.nasa.gov/earthobservation-data/near-real-time/ firms / mcd14ml (accessed on 11 June 2021).

72. ECMWF Fire Danger Indices Historical Data from the Copernicus Emergency Management Service. Available online: https: / /cds.climate.copernicus.eu/cdsapp\#!/home (accessed on 29 January 2020).

73. ECMWF CAMS Global Reanalysis (EAC4) Monthly Averaged Fields. Available online: https://ads.atmosphere.copernicus.eu/ cdsapp\#! / dataset/cams-global-reanalysis-eac4-monthly?tab=overview (accessed on 15 July 2021).

74. Mann, H.B. Nonparametric Tests Against Trend. Econometrica 1945, 13, 245. [CrossRef]

75. Hamed, K.; Rao, A.R. A modified Mann-Kendall trend test for autocorrelated data. J. Hydrol. 1998, 204, 182-196. [CrossRef]

76. Yue, S.; Wang, C.Y. Applicability of prewhitening to eliminate the influence of serial correlation on the Mann-Kendall test. Water Resour. Res. 2002, 38, 4-1-4-7. [CrossRef]

77. Neeti, N.; Eastman, J.R. A Contextual Mann-Kendall Approach for the Assessment of Trend Significance in Image Time Series. Trans. GIS 2011, 15, 599-611. [CrossRef]

78. Chandler, R.E.; Richard, E.; Scott, E.M. Statistical Methods for Trend Detection and Analysis in the Environmental Sciences; Chandler, R.E., Scott, E.M., Eds.; John Wiley \& Sons, Ltd.: Chichester, UK, 2011; ISBN 9781119991571.

79. Hussain, M.M.; Mahmud, I. pyMannKendall: A python package for non parametric Mann Kendall family of trend tests. J. Open Source Softw. 2019, 4, 1556. [CrossRef]

80. Santos, F.L.M.; Libonati, R.; Peres, L.F.; Pereira, A.A.; Narcizo, L.C.; Rodrigues, J.A.; Oom, D.; Pereira, J.M.C.; Schroeder, W.; Setzer, A.W. Assessing VIIRS capabilities to improve burned area mapping over the Brazilian Cerrado. Int. J. Remote. Sens. 2020, 41, 8300-8327. [CrossRef]

81. Pereira, A.A.; Pereira, J.M.C.; Libonati, R.; Oom, D.; Setzer, A.W.; Morelli, F.; Machado-Silva, F.; De Carvalho, L.M.T. Burned Area Mapping in the Brazilian Savanna Using a One-Class Support Vector Machine Trained by Active Fires. Remote. Sens. 2017, 9, 1161. [CrossRef]

82. Rodrigues, J.A.; Libonati, R.; Pereira, A.A.; Nogueira, J.M.P.; Santos, F.L.M.; Peres, L.F.; Rosa, A.S.; Schroeder, W.; Pereira, J.M.; Giglio, L.; et al. How well do global burned area products represent fire patterns in the Brazilian Savannas biome? An accuracy assessment of the MCD64 collections. Int. J. Appl. Earth Obs. Geoinf. 2019, 78, 318-331. [CrossRef]

83. Gomes, L.; Miranda, H.S.; Bustamante, M.M.D.C. How can we advance the knowledge on the behavior and effects of fire in the Cerrado biome? For. Ecol. Manag. 2018, 417, 281-290. [CrossRef]

84. Barradas, A.C.S.; Borges, M.A.; Costa, M.M.; Ribeiro, K.T. Paradigmas da Gestão do Fogo em Áreas Protegidas no Mundo e o Caso da Estação Ecológica Serra Geral do Tocantins. Biodiversidade Bras. BioBrasil 2020, 71-86. [CrossRef]

85. Fidelis, A. Is fire always the "bad guy"? Flora 2020, 268, 151611. [CrossRef]

86. Tibshirani, R.J.; Efron, B. An Introduction to the Bootstrap; CRC Press: Boca Raton, FL, USA, 1993; Volume 57, pp. 1-436.

87. Van Wilgen, B.W.; Govender, N.; Biggs, H.C. The contribution of fire research to fire management: A critical review of a long-term experiment in the Kruger National Park, South Africa. Int. J. Wildland Fire 2007, 16, 519. [CrossRef]

88. Van Wilgen, B.W.; Everson, C.S.; Trollope, W.S.W. Fire Management in Southern Africa: Some Examples of Current Objectives, Practices, and Problems. In Fire in the Tropical Biota; Springer: Berlin/Heidelberg, Germany, 1990; pp. $179-215$.

89. Van Wilgen, B.W.; Govender, N.; Biggs, H.C.; Ntsala, D.; Funda, X.N. Response of Savanna Fire Regimes to Changing FireManagement Policies in a Large African National Park. Conserv. Biol. 2004, 18, 1533-1540. [CrossRef]

90. Wiedinmyer, C.; Hurteau, M. Prescribed Fire As a Means of Reducing Forest Carbon Emissions in the Western United States. Environ. Sci. Technol. 2010, 44, 1926-1932. [CrossRef]

91. Campagnolo, M.; Libonati, R.; Rodrigues, J.; Pereira, J. A comprehensive characterization of MODIS daily burned area mapping accuracy across fire sizes in tropical savannas. Remote. Sens. Environ. 2020, 252. [CrossRef]

92. Price, O.F.; Russell-Smith, J.; Watt, F. The influence of prescribed fire on the extent of wildfire in savanna landscapes of western Arnhem Land, Australia. Int. J. Wildland Fire 2012, 21, 297-305. [CrossRef]

93. Bird, R.B.; Codding, B.; Kauhanen, P.G.; Bird, D.W. Aboriginal hunting buffers climate-driven fire-size variability in Australia's spinifex grasslands. Proc. Natl. Acad. Sci. USA 2012, 109, 10287-10292. [CrossRef]

94. Mistry, J.; Berardi, A.; Andrade, V.; Krahô, T.; Krahô, P.; Leonardos, O. Indigenous Fire Management in the cerrado of Brazil: The Case of the Krahô of Tocantíns. Hum. Ecol. 2005, 33, 365-386. [CrossRef]

95. Alvarado, S.T.; Silva, T.S.F.; Archibald, S. Management impacts on fire occurrence: A comparison of fire regimes of African and South American tropical savannas in different protected areas. J. Environ. Manag. 2018, 218, 79-87. [CrossRef] 
96. Fernandes, P.M.; Botelho, H.S. A review of prescribed burning effectiveness in fire hazard reduction. Int. J. Wildland Fire 2003, 12, 117-128. [CrossRef]

97. Hoffmann, W.A.; Solbrig, O.T. The role of topkill in the differential response of savanna woody species to fire. For. Ecol. Manag. 2003, 180, 273-286. [CrossRef]

98. Arkle, R.S.; Pilliod, D.S.; Welty, J.L. Pattern and process of prescribed fires influence effectiveness at reducing wildfire severity in dry coniferous forests. For. Ecol. Manag. 2012, 276, 174-184. [CrossRef]

99. Nowell, H.K.; Holmes, C.D.; Robertson, K.; Teske, C.; Hiers, J.K. A New Picture of Fire Extent, Variability, and Drought Interaction in Prescribed Fire Landscapes: Insights from Florida Government Records. Geophys. Res. Lett. 2018, 45, 7874-7884. [CrossRef]

100. Schreiner, A.J.; Schmit, T.J.; Menzel, W.P. Observations and trends of clouds based on GOES sounder data. J. Geophys. Res. Space Phys. 2001, 106, 20349-20363. [CrossRef]

101. Randerson, J.T.; Chen, Y.; van der Werf, G.; Rogers, B.M.; Morton, D.C. Global burned area and biomass burning emissions from small fires. J. Geophys. Res. Space Phys. 2012, 117. [CrossRef]

102. Mouillot, F.; Schultz, M.; Yue, C.; Cadule, P.; Tansey, K.; Ciais, P.; Chuvieco, E. Ten years of global burned area products from spaceborne remote sensing-A review: Analysis of user needs and recommendations for future developments. Int. J. Appl. Earth Obs. Geoinf. 2014, 26, 64-79. [CrossRef]

103. Zhu, C.; Kobayashi, H.; Kanaya, Y.; Saito, M. Size-dependent validation of MODIS MCD64A1 burned area over six vegetation types in boreal Eurasia: Large underestimation in croplands. Sci. Rep. 2017, 7, 1-9. [CrossRef]

104. Hall, J.V.; Loboda, T.V.; Giglio, L.; McCarty, G.W. A MODIS-based burned area assessment for Russian croplands: Mapping requirements and challenges. Remote. Sens. Environ. 2016, 184, 506-521. [CrossRef]

105. Tsele, P.; Wessels, K.; Botai, J.; Archibald, S.; Swanepoel, D.; Steenkamp, K.; Frost, P. Validation of the Two Standard MODIS Satellite Burned-Area Products and an Empirically-Derived Merged Product in South Africa. Remote. Sens. 2014, 6, 1275-1293. [CrossRef]

106. Tsela, P.L.; van Helden, P.; Frost, P.; Wessels, K.; Archibald, S. Validation of the MODIS burned-area products across different biomes in South Africa. In Proceedings of the 2010 IEEE International Geoscience and Remote Sensing Symposium, Honolulu, HI, USA, 25-30 July 2010; pp. 3652-3655.

107. Fornacca, D.; Ren, G.; Xiao, W. Performance of Three MODIS Fire Products (MCD45A1, MCD64A1, MCD14ML), and ESA Fire_CCI in a Mountainous Area of Northwest Yunnan, China, Characterized by Frequent Small Fires. Remote. Sens. 2017, 9, 1131. [CrossRef]

108. Cochrane, M.A.; Bowman, D.M.J.S. Manage fire regimes, not fires. Nat. Geosci. 2021, 14, 455-457. [CrossRef]

109. Souza, C.; Shimbo, J.Z.; Rosa, M.; Parente, L.; Alencar, A.A.; Rudorff, B.; Hasenack, H.; Matsumoto, M.; Ferreira, L.G.; Souza-Filho, P.; et al. Reconstructing Three Decades of Land Use and Land Cover Changes in Brazilian Biomes with Landsat Archive and Earth Engine. Remote. Sens. 2020, 12, 2735. [CrossRef]

110. Agee, J.K.; Bahro, B.; Finney, M.A.; Omi, P.N.; Sapsis, D.B.; Skinner, C.N.; van Wagtendonk, J.W.; Weatherspoon, C.P. The use of shaded fuelbreaks in landscape fire management. For. Ecol. Manag. 2000, 127, 55-66. [CrossRef]

111. Santopuoli, G.; Cachoeira, J.N.; Marchetti, M.; Viola, M.R.; Giongo, M. Explore inhabitants' perceptions of wildfire and mitigation behaviours in the Cerrado biome, a fire-prone area of Brazil. Ann. Silvic. Res. 2017, 41, 29-40.

112. Flannigan, M.; Cantin, A.S.; de Groot, W.J.; Wotton, M.; Newbery, A.; Gowman, L.M. Global wildland fire season severity in the 21st century. For. Ecol. Manag. 2013, 294, 54-61. [CrossRef]

113. Nikolakis, W.D.; Roberts, E. Indigenous fire management: A conceptual model from literature. Ecol. Soc. 2020, 25, 11. [CrossRef]

114. Fernandes, P.M. Scientific support to prescribed underburning in southern Europe: What do we know? Sci. Total Environ. 2018, 630, 340-348. [CrossRef] 